Article

\title{
Using Waste in Producing Bio-Composite Mycelium Bricks
}

\author{
Jason Maximino C. Ongpeng * $\mathbb{D}$, Edward Inciong, Vince Sendo, Crizia Soliman $\mathbb{D}$ and \\ Adrian Siggaoat \\ Department of Civil Engineering, De La Salle University Manila, 2401 Taft Ave., Manila 0922, Philippines; \\ edward_inciong@dlsu.edu.ph (E.I.); vince_sendo@dlsu.edu.ph (V.S.); crizia_soliman@dlsu.edu.ph (C.S.); \\ adrian_siggaoat@dlsu.edu.ph (A.S.) \\ * Correspondence: jason.ongpeng@dlsu.edu.ph
}

Received: 21 June 2020; Accepted: 28 July 2020; Published: 31 July 2020

check for updates

\begin{abstract}
One of the major causes of an increase in the consumption of resources is the progress of the construction industry. Although it leads to new technologies, it heavily contributes to global warming. In this study, the use of sustainable construction materials from waste in brick production with mycelium as a binder is investigated. The ability of mycelium, the root fibers of fungi, obtained from microorganisms is used as stabilizing and binding material on bricks. Forty-eight brick specimens from six design mixes were produced with a size of $200 \mathrm{~mm}$ length $\times 90 \mathrm{~mm}$ width $\times 60 \mathrm{~mm}$ height. The mechanical tests conducted were compressive and flexural strength. The changes in weight were recorded against its age to monitor the progress of mycelium growth inside the brick specimens. From the test, bricks made from sawdust and rice bran with mycelium had an increase of $31.0 \%$ to $38.5 \%$ in average compressive strength compared to the non-mycelium bricks, respectively. Furthermore, the bricks with mycelium experienced an increase in both flexural strength and midpoint displacement for all types of bricks (rice bran, sawdust, and clay). These mycelium-induced bricks can reduce the use and consumption of traditional construction materials with enhanced mechanical properties.
\end{abstract}

Keywords: bio-composite; mycelium; wastes; bricks

\section{Introduction}

The increased demand in agriculture and industrialization and accelerated growth of population has brought about large amounts of waste and pollution. In the field of construction, this trend is heavily manifested as environmentally harmful methods of manufacturing have caused the deterioration of the environment. Therefore, the motivation for the development of an innovative material in construction has become of interest to researchers and practitioners. Versatility, in terms of low energy consumption, sustainable and highly functional, is the new norm for these new materials. In order to integrate these alternative materials to modern society, it is vital for technology to progress, adapt, and increase the acceptance of such products. Hence, searching for alternative approaches that are environmentally friendly materials could lead to a more sustainable future.

One of the emerging topics in sustainable construction building materials is the use of bio-composite material, such as mycelium. Mycelium is comprised of hyphae and root-like plant structures with the ability to allow the fungus to consume the nutrients from its waste substrate. In the study of Abhijith et al., mycelium-based materials have the potential to be a material of choice for various applications [1]. Mycelium would bind material together by growing into its substrate. The material could have the capacity to grow on lignocellulosic substrates. This could also be vital to the strength and its capability to activate its physiological properties [2]. The world's second most abundant biopolymer 
is Chitin which is a chemical molecule that comprises mycelium. Chitin is a high tensile strength, poly-crystalline polymeric acetylglucosamine, which is responsible for the tensile strength of the mycelium, thus, providing reinforcing capacity strength to the fibrous network [3]. There are studies on enhancing properties through natural additives which cause stronger bond at the interfaces [4].

Several studies related to building materials, for both structural or non-structural applications, were done from literatures. Use of mycelium to construction, design, and educational sectors is available [5]. In the construction sector, development of load-bearing mycelium bricks and concrete with an average compressive strength of $5.7 \mathrm{MPa}$ and $22.5 \mathrm{MPa}$, respectively, was achieved [6]. Biopolymers for architectural cladding has also been developed towards sustainable construction and building materials [7]. The growth of mycelium can be studied and use it for intervention in existing architecture and solid building materials grown from fragmented waste materials [8]. Since bio-composites may react with moisture, materials with mycelium can be maximized once water vapor is removed [9].

It is recommended to explore the development of new stabilization agents. This was done through a review on life cycle assessment comparing traditional bricks and alternative bricks with organic and inorganic materials [10]. In order to achieve sustainable construction alternatives for bricks used in interior walls were no substantial wetting and drying occur, this study focused on the utilization of waste products such as: Rice bran (RB), sawdust (SD), and coconut husk (CH) with mycelium. The RB/CH and SD are byproducts of rice milling/coconut processes and woodworking operations, respectively. The binder that holds the substrate together is with the use of a bio-composite called mycelium (M). With the utilization of agricultural and industrial waste materials as substrate and reduction on the use of cement binders, the researchers aim to formulate and produce mycelium bricks that can achieve an environmentally friendly product that is of par with standard construction building materials. The contribution of this paper in the field of sustainable construction material are the design mix, methodology, and the results of compressive and flexural strength.

\section{Materials and Method}

The binder in the produced bricks is from mycelium. The materials used for the development of mycelium are rice and sugarcane molasses (SCM). The matrix that the mycelium binds are the substrates $\mathrm{RB}, \mathrm{SD}$, and $\mathrm{CH}$. The $\mathrm{RB}, \mathrm{SD}$, and $\mathrm{CH}$ contains nutrients that achieve mycelium growth in the matrix. As a control specimen, clay $(C)$ brick was also produced, which are common building materials. Seen in Table 1 are the types of specimens and the number of specimens for the compressive and flexural test. The RB design mix contains a ratio of 5:2:1 by mass for $\mathrm{C}: \mathrm{RB}: \mathrm{CH}$ with $350 \mathrm{~mL}$ water added to the mix. The SD mix contains a ratio of 5:3:1 by mass for C:SD:CH with $450 \mathrm{~mL}$ of water added to this mix. The $\mathrm{C}$ mix was designed using conventional brick production with varying water in attaining a workable mix.

SCM ingredients were commercially available, while the $\mathrm{RB}$ and $\mathrm{CH}$ were acquired from local farms and factories and SD was obtained from lumber wastes. In addition, paper, two (2) plastic containers, and airtight wrappers were also gathered. Figure 1a shows the items mentioned. Seen in Figure $1 \mathrm{~b}$ is the steel brick mold used which was measured to have the dimensions, $200 \mathrm{~mm}$ length $\times$ $90 \mathrm{~mm}$ width $\times 60 \mathrm{~mm}$ height. The mold comprises of 4 bricks in one production. After creating the bricks with 33 days of incubation, a laboratory oven (kept at $110^{\circ}$ to $115^{\circ} \mathrm{C}$ for not less than $24 \mathrm{~h}$ ) was used for drying. Drying of the bricks is required to prohibit any further growth of the mycelium.

Figure 2 shows the raw ingredients used. For the design mixes, Clay $(\mathrm{C})$ and Coco Husk $(\mathrm{CH})$ remained as the constant ingredient for the substrate in the four design mixes with agricultural wastes. Sugar Cane Molasses (SCM) was utilized to act as the mycelium in serum form for the researchers to securely handle and later add the mycelium to the substrate mixes. An immensely common agricultural food waste in the Philippines, Rice Bran (RB) can be easily obtained from local farms and gardens in the country. RB was employed as a substrate material with the intention of obtaining a faster rate of growth in the material and acted both as an additional filler material and stabilizer for the substrate. 
Hardwood Sawdust (SD) is a commercially available waste material generated from wood workshops and construction sites which were sieved to smaller particles. Coco Husk $(\mathrm{CH})$ was collected from a coconut farm as it is a highly common agricultural waste in the Philippines that is usually disposed of after use. In the mix design, $\mathrm{CH}$ was used as an additional substrate for mycelium nutrients for growth. $\mathrm{CH}$ was also sieved into fine particles and was utilized for all the design mixes.

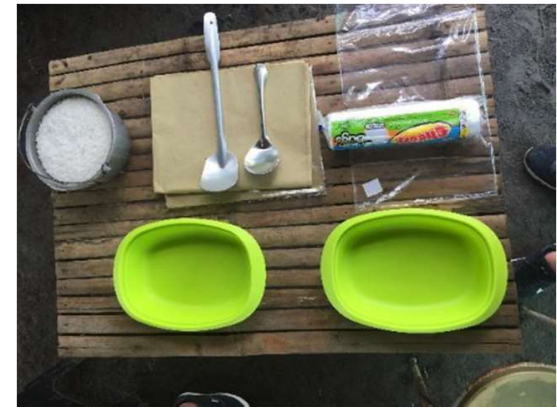

(a)

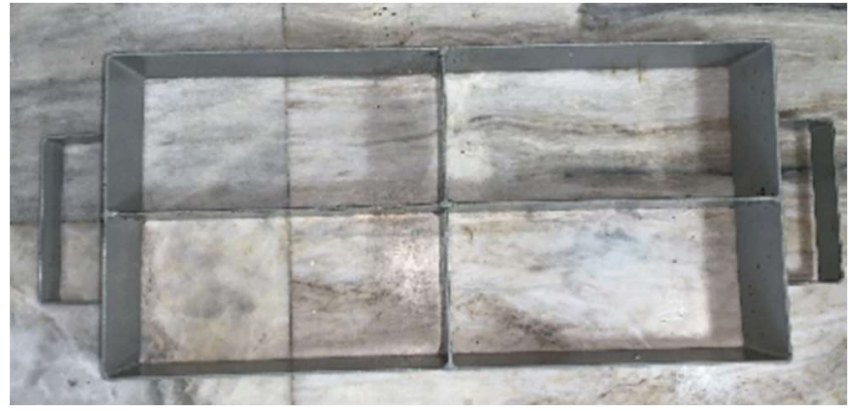

(b)

Figure 1. (a) Materials for mycelium substrate production; (b) brick molds used.

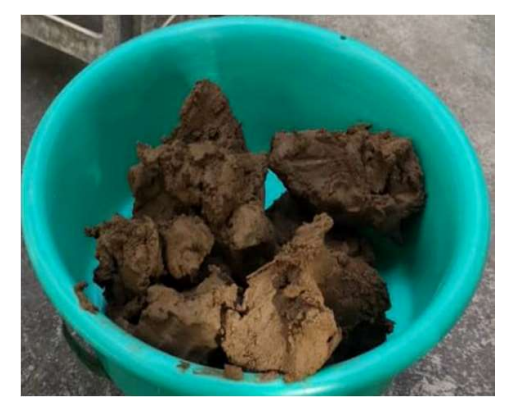

(a)

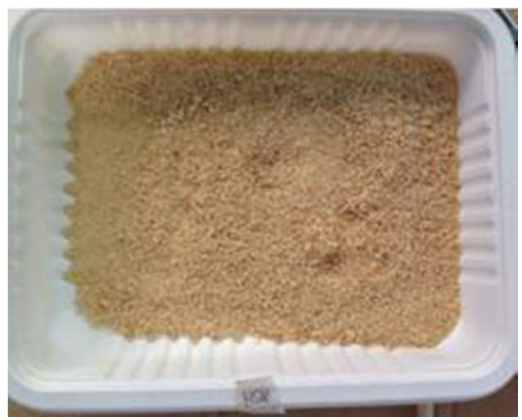

(d)

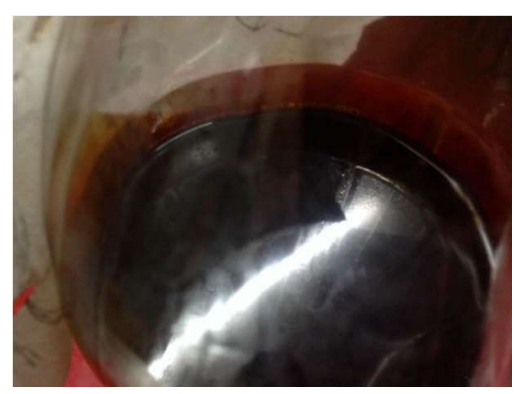

(b)

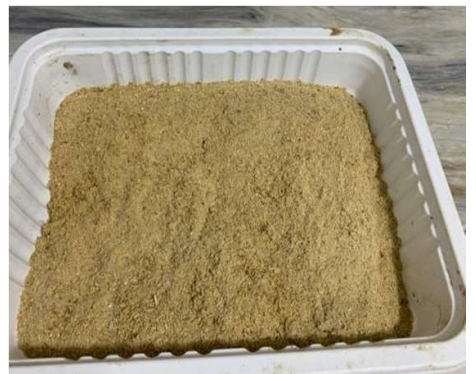

(c)

Figure 2. (a) Clay; (b) sugar cane molasses; (c) rice bran; (d) sawdust (e) coconut husks.

Seen in Figure 3 is the process made in the production bio-composite brick. The methodology begins with the acquisition of the mycelium fungi from underneath a bamboo shoot. One kilogram of rice in a plastic container, as shown in Figure 3a, was the initial main substrate used and buried below the soil near the bamboo shoot. The container was left underground for a total of five (5) days. This was vital to allow the substrate to hold the fungal tissue. After the said period, the mycelium was segregated by the researchers from the rice substrate. This can be observed in Figure 3b. After the segregation, the mycelium was mixed with $1 \mathrm{~L}$ of sugarcane molasses (SCM) which was stored in a 1.5 L PET bottle. There is then an inoculation period of five (5) days in constant ambient temperature, before it was used in the brick production as a mycelium serum. 
Table 1. Composition and number of specimens.

\begin{tabular}{|c|c|c|c|c|c|}
\hline Specimen Mix Design & $\begin{array}{c}\mathrm{C}: \mathrm{X}: \mathrm{CH} \\
\text { by Mass }\end{array}$ & Added Water $(\mathrm{mL})$ & Mycelium Serum & $\begin{array}{l}\text { Number of Specimens } \\
\text { for Compressive Tests }\end{array}$ & $\begin{array}{l}\text { Number of Specimens } \\
\text { for Flexural Tests }\end{array}$ \\
\hline Rice Bran bricks (RB) & $5: 2: 1$ & 350 & Without & 4 & 4 \\
\hline Rice Bran with mycelium bricks (RBM) & $5: 2: 1$ & 350 & With & 4 & 4 \\
\hline Sawdust bricks (SD) & $5: 3: 1$ & 450 & Without & 4 & 4 \\
\hline Sawdust with mycelium bricks (SDM) & $5: 3: 1$ & 450 & With & 4 & 4 \\
\hline Clay Bricks (C) & $5: 0: 0$ & Variable & Without & 4 & 4 \\
\hline Clay with mycelium bricks (CM) & 5:0:0 & Variable & With & 4 & 4 \\
\hline
\end{tabular}




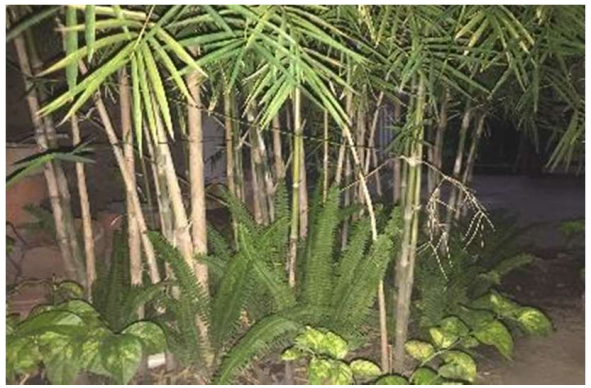

(a)

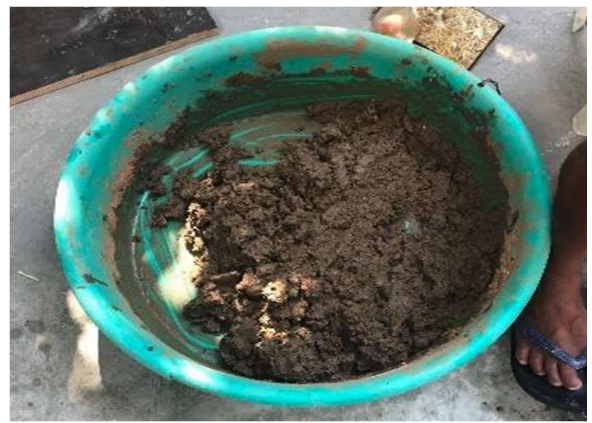

(c)

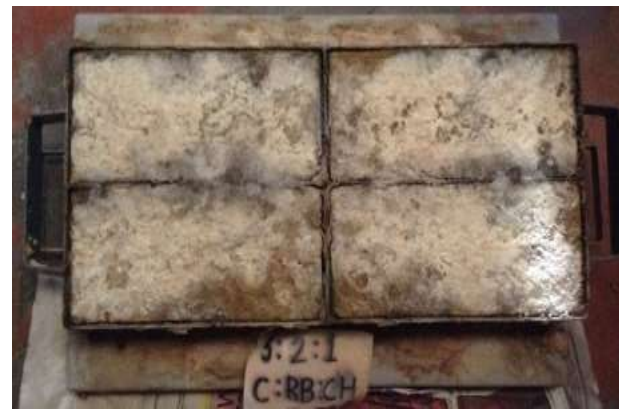

(e)

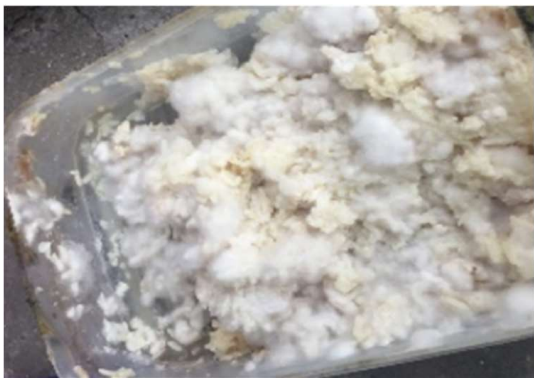

(b)

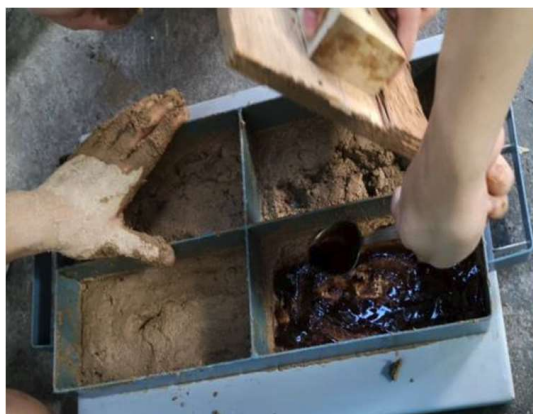

(d)

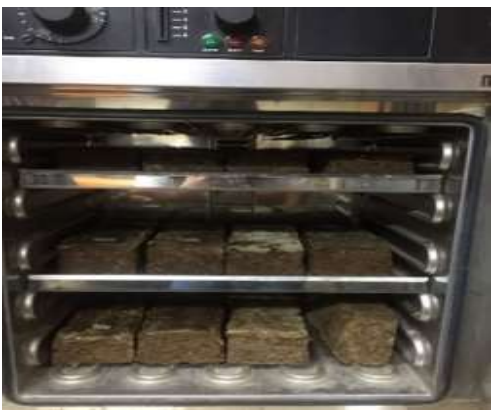

(f)

Figure 3. (a) Rice substrate buried under bamboo; (b) mycelium serum preparation; (c) weighing and mixing of main substrate mix; (d) production of bricks; (e) curing of mycelium bricks; (f) oven drying of bricks.

The researchers arranged substrate design mix based on material availability and from the waste substrates utilized by Zurbano et al. (2017) for mycelium growth [11]. Mass was utilized as the basis for the design mix ratio. Sieve no. $150 \mu \mathrm{m}$ was used to achieve the particle size of SD and CH. Water used in all substrate mixes is distilled water. As seen in Figure 3c, the agricultural wastes were mixed together manually to form the substrate. Afterwards, the mycelium serum was added to the main substrate design mix, as observed in Figure 3d. One tablespoon of mycelium serum for one kilogram of ingredients was used for the mycelium serum-substrate ratio. After mixing, the mycelium bricks placed in mold are stored inside a room with no sunlight at a constant temperature for a period of twenty-five (25) days incubation as seen in Figure 3e. During this incubation period, the weight of the bricks specimens was recorded daily until all the mechanical tests were performed. After the incubation, the mycelium bricks were oven-dried for 1 day in order to prohibit the growth of the mycelium in the bricks. The range of temperature used in the oven drying the RB, RBM, SD and SDM bricks was at 110 to $115^{\circ} \mathrm{C}$, while oven-fired bricks for $\mathrm{C}$ and $\mathrm{CM}$ observed a minimum temperature of $900{ }^{\circ} \mathrm{C}$ and a maximum temperature of $1100{ }^{\circ} \mathrm{C}$. A further four days was allowed for, so the bricks could harden after the oven process, as shown in Figure 3f. Another four days was consumed for the curing period of the bricks. The total number of days from the start of production until testing is 34 days. 
Compressive and flexural tests were performed after the production of the bricks after 34 days. The universal testing machine (UTM) was used to administer mechanical tests. The compression tests were implemented in accordance with ASTM C67. The compressed bricks, after testing, are seen in Figure 4a. In accordance with ASTM E518, the flexural tests were performed. The set-up for the latter test was a three-point loading which obtained the flexural capacity of the brick. This flexural test set-up can be seen in Figure $4 b$, which shows the specimen with equally spaced supports on both ends of the brick. The midpoint displacement, due to the force applied, was recorded.

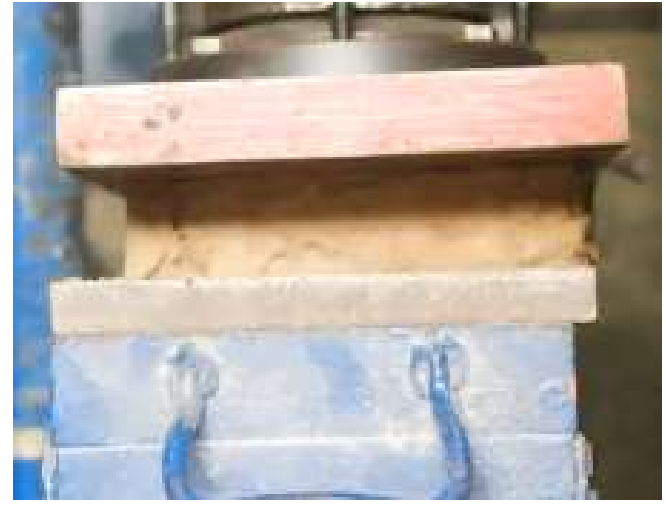

(a)

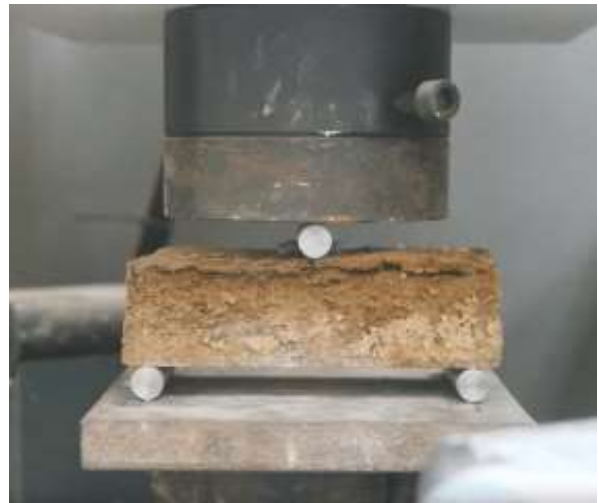

(b)

Figure 4. (a) Brick compression testing; (b) brick flexural strength testing.

\section{Results and Discussion}

\subsection{Weight against Age}

The weights of the brick specimens for a compressive test at the 34th day were recorded daily and graphed against the number of days. The relationship between weight and age of the brick specimen is seen in Figure 5. The weight of the mycelium bricks is always greater than the non-mycelium bricks, signifying that the additional weight was contributed from the presence of mycelium. Since it is difficult to determine the mycelium content inside the brick specimens, it is assumed that the average difference between mycelium bricks and the non-mycelium bricks is the estimated mycelium content. Based on the figure, CM bricks had the highest weight, followed by C, RBM, RB, SDM, and SD. The average difference of weight between $\mathrm{CM}$ and $\mathrm{C}$ bricks was found to be $12.25 \mathrm{~g}$, while SDM and SD bricks incurred the highest difference at $57 \mathrm{~g}$. Lastly, the difference between RBM and RB bricks was found to be $29.75 \mathrm{~g}$. Clay bricks produced less estimated mycelium content, while SD bricks provided the highest mycelium content.

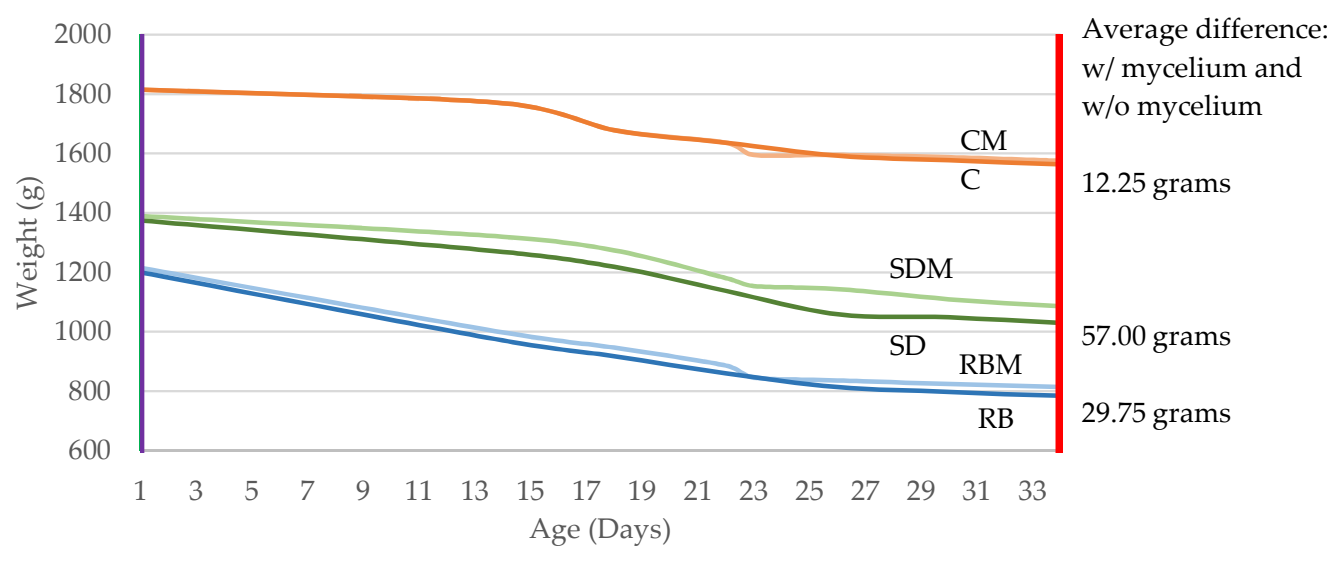

Figure 5. Estimated mycelium content is taken as the average difference of the weight between mycelium and non-mycelium bricks. 


\subsection{Compressive Strength}

The strength test results of the mycelium-induced bricks and regular bricks were obtained. For the compressive test, four specimens of each design mix were tested. From this test, all the mycelium-induced brick specimens achieved the 3.5 MPa minimum compressive strength for masonry bricks [12] as seen in Figure 6. Moreover, the majority of the average values of the compressive strength for bricks without mycelium attained the minimum requirement with the exception of the RB specimens. The highest compressive strength test results can be seen on the $C$ and $C M$ design mixes. In the results, it can also be extracted that there was a $38.5 \%$ increase in compressive strength from RB to RBM mixes. Then for the SD to SDM substrates, there was an increase of 31.0\% in compressive strength. The presence of mycelium can be inferred to be the prevailing substance that caused the increase in strength of the bricks. It acted as a fibrous-binding material or a bio-composite binder or stabilizer which effectively increased the capacity of the mycelium-induced bricks. The mycelium-induced bricks also appeared to be more ductile as compared to the regular substrate bricks without mycelium. It can be seen particularly in the RBM and SDM bricks that particles did not entirely collapse or had been crushed, and it remained intact with very minimal cracks after the test.

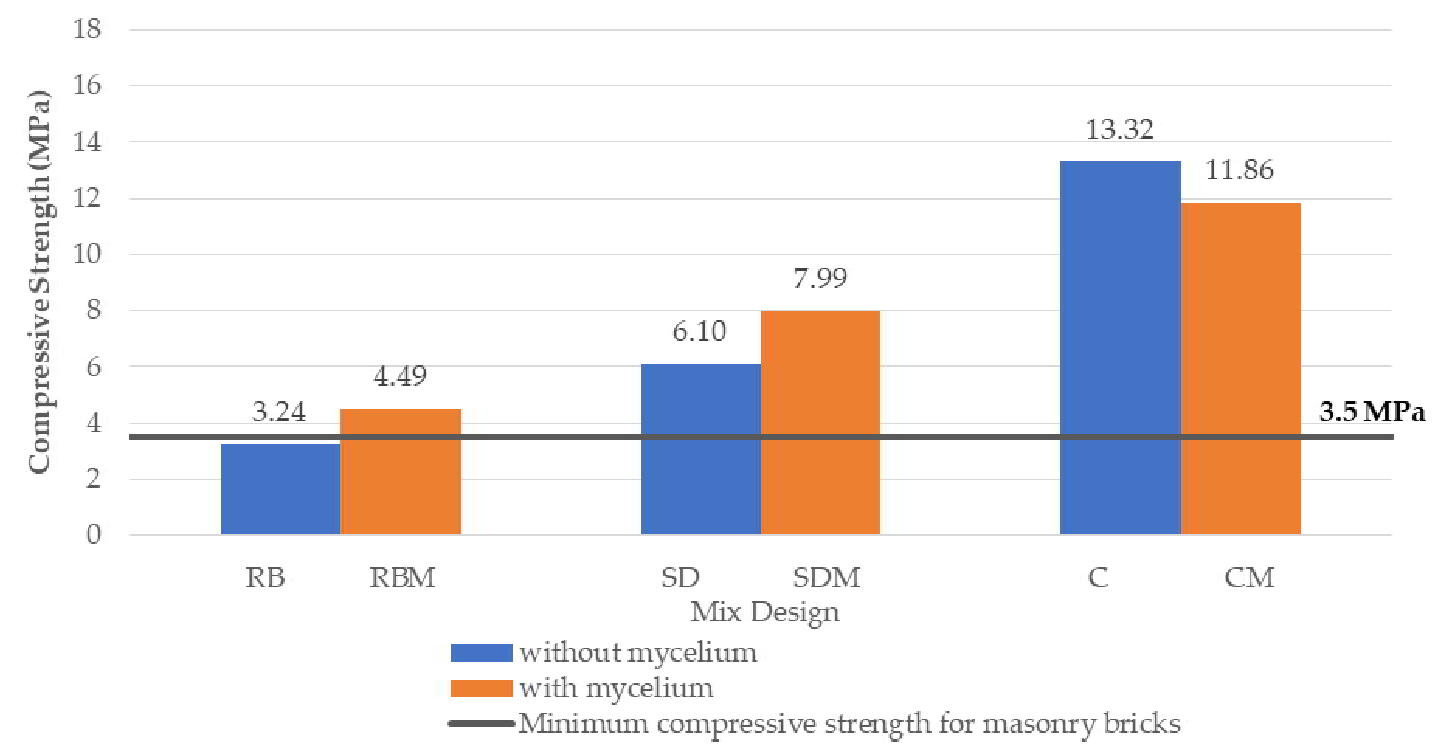

Figure 6. Compressive strength of bricks with and without mycelium.

Figure 7 shows the box and whisker plots of the six design mixes of the brick specimens' compressive strength results. It shows from top to bottom, the maximum value as the top whisker, first quartile as the top of box, median as the circle, third quartile as the bottom of box, and the minimum value as bottom whisker. The design mixes were arranged left to right from least to greatest median. It can be observed in the figure that the variation of RB, RBM, SD, and SDM is small (less than $2 \mathrm{MPa}$ ) compared to $\mathrm{CM}$ and $\mathrm{C}$. The greatest variation is seen in $\mathrm{CM}$, since there were minimal mycelium present, an average of $12.25 \mathrm{~g}$ at 34 days, leading to few and inconsistent mycelium fiber networks present in achieving cohesive and better compressive results.

\subsection{Flexural Strength}

Table 2 shows the average values of total midpoint displacement and flexural strength. A total of four specimens were tested for each design mixes. The equation for the flexural strength of the brick specimen is shown in Equation (1). The independent load variable P was obtained during the flexural strength test at failure. The brick dimensions per specimen were measured and utilized in the computation for flexural strength. SDM specimens were found to have the flexural strength value at $0.473 \mathrm{MPa}$, while its average maximum midpoint displacement was at $2.937 \mathrm{~mm}$. It achieved higher 
displacement than the brick without mycelium, due to the presence of fibers. Notably, RBM obtained the highest force as compared to the other specimen mix designs with mycelium. It proved that the growth of mycelium was effective in rice bran as substrate.

$$
\sigma f=\frac{3 P L}{2 b d^{2}}
$$

where:

$\sigma f$ - Flexural Strength (MPa)

$P$ - Recorded Maximum Load (N)

$L$ - Length of the brick (m)

$b$ - Width of the brick (m)

$d$ - Height of the brick (m)

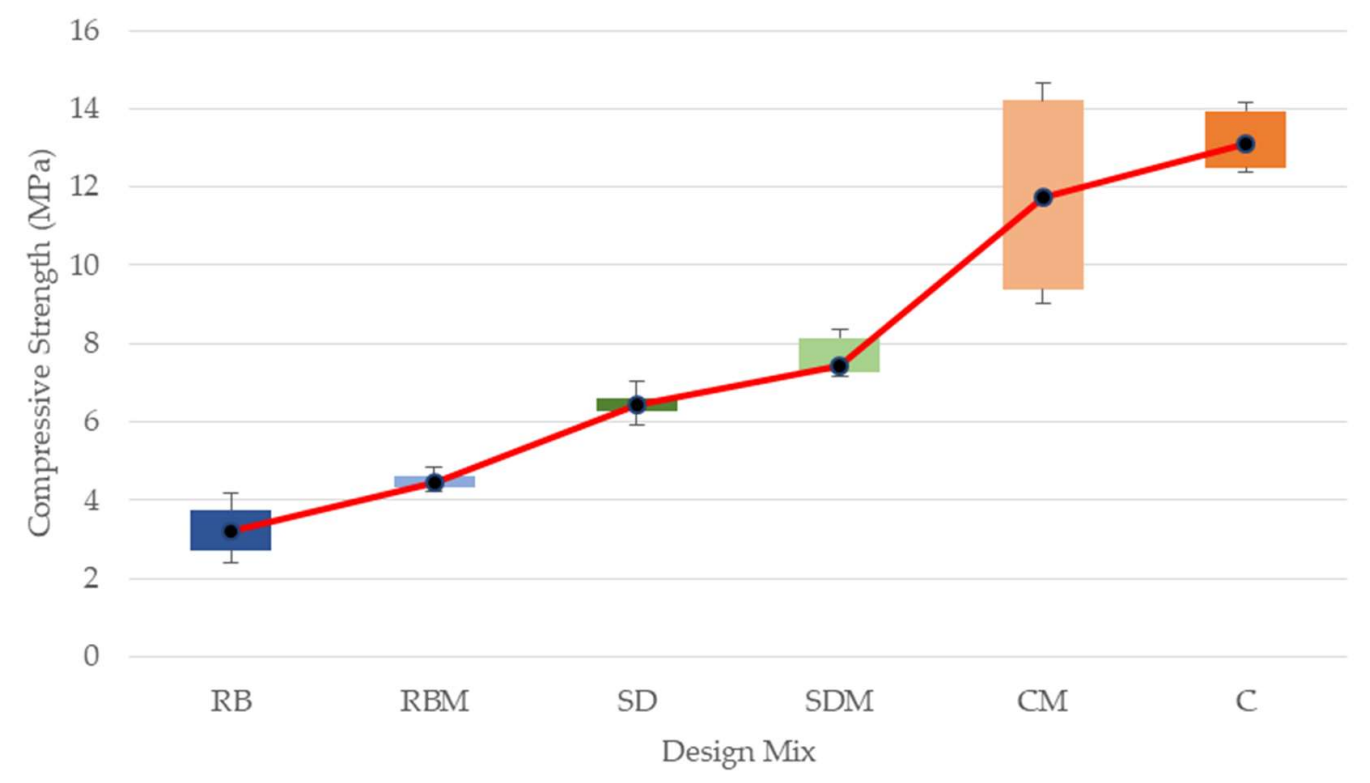

Figure 7. Box and whisker plots of each design mix.

Table 2. Average values of the total displacement and flexural strength.

\begin{tabular}{ccc}
\hline Specimen Mix Design & $\begin{array}{c}\text { Average Maximum Midpoint } \\
\text { Displacement (mm) }\end{array}$ & Average $\boldsymbol{\sigma f}$ (MPa) \\
\hline Rice Bran bricks (RB) & 0.967 & 1.013 \\
Rice Bran with mycelium bricks (RBM) & 1.977 & 0.916 \\
Sawdust bricks (SD) & 2.937 & 0.473 \\
Sawdust with mycelium bricks (SDM) & 2.764 & 0.962 \\
Clay Bricks (C) & 0.870 & 0.629 \\
Clay with mycelium bricks (CM) & 1.202 & 0.878 \\
\hline
\end{tabular}

Figure 8 shows the force-displacement under three-point bending test from a single specimen representing the design mix. The midpoint displacement corresponding to the recorded maximum load increases when the mycelium is added. In addition, the smallest and highest displacement corresponding to the recorded maximum load is $C$ and SDM, respectively. Further investigation is recommended to correlate the mycelium content and increase in flexural properties. Figure 9 shows the brick specimens RBM and SDM after testing experiencing tensile failure with cracks forming at the bottom and positioned in the middle, as seen in the encircled portion of the pictures. 


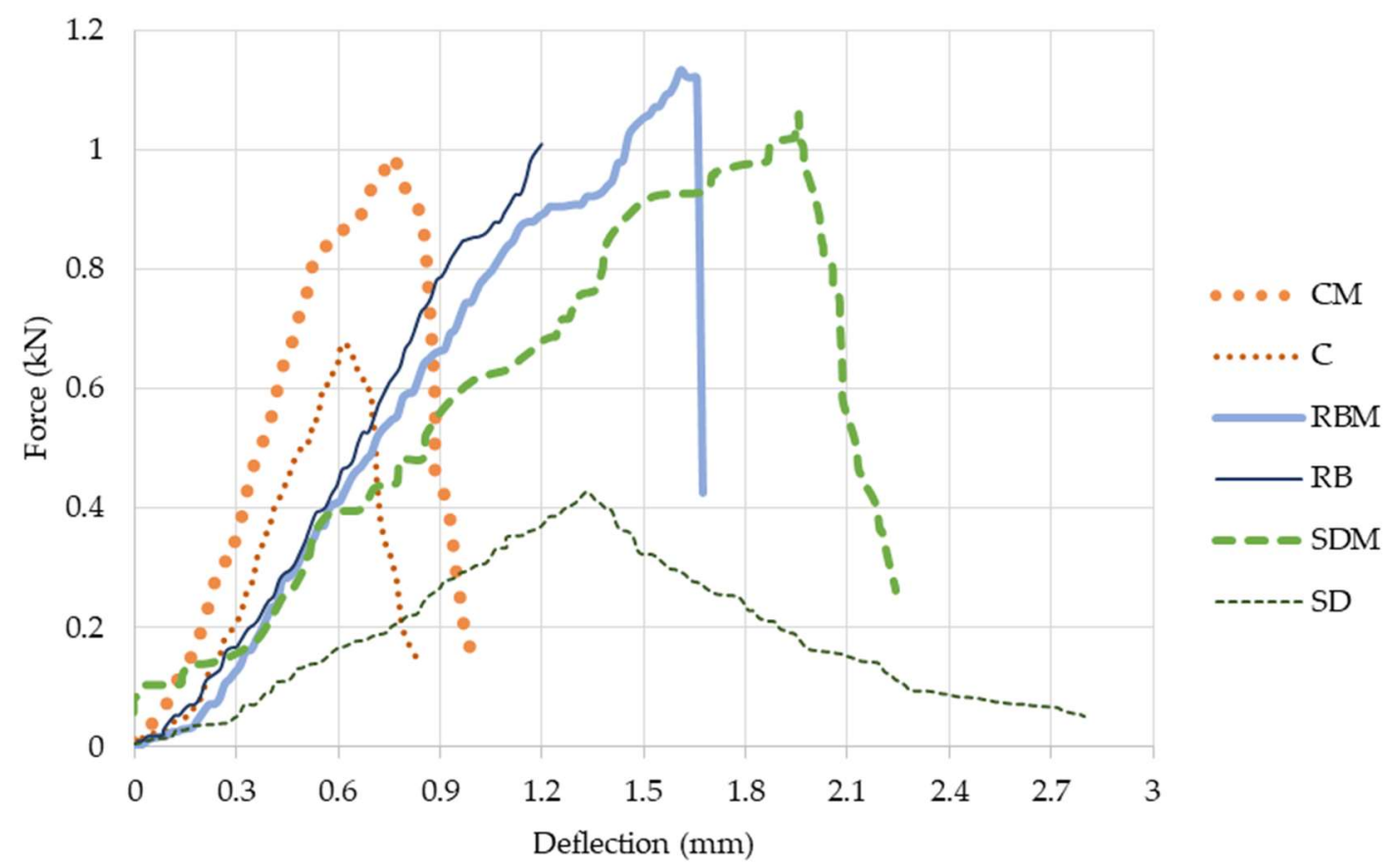

Figure 8. Force-displacement diagram of all mix design (C, CM, RB, RBM, SD, and SDM) taken from sample specimen.

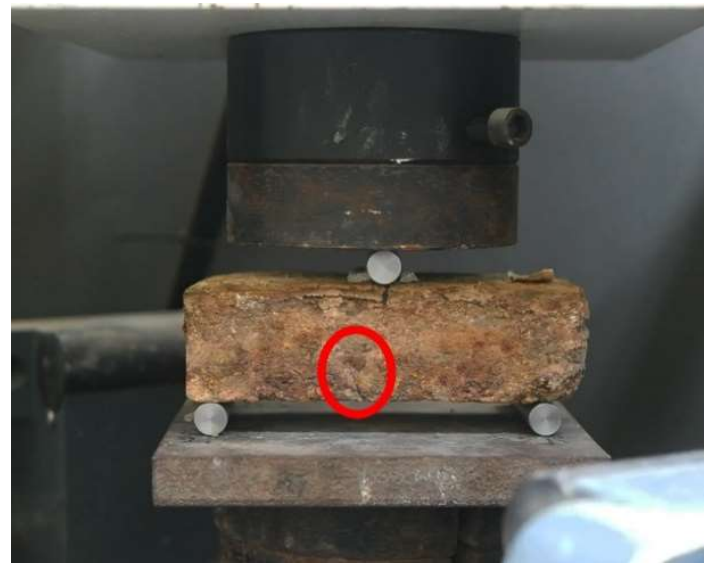

(a)

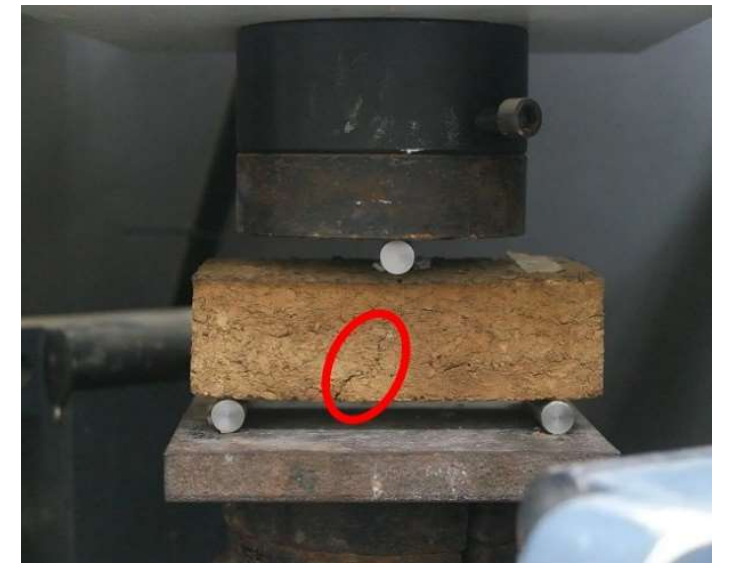

(b)

Figure 9. (a) Rice Bran with mycelium (RBM) brick specimen tensile failure crack; (b) sawdust with mycelium (SDM) brick specimen tensile failure crack.

\subsection{Compressive Strength, Flexural Strength, and Weight}

In Figure 10, the average compressive strength, an average maximum force under 3-point loading test, and weight are correlated. From top to bottom, the arrangement of the bars are defined as $\mathrm{CM}$, C, SDM, SD, RBM and RB. The least compressive strength for RB and SD are those without mycelium, compared to the $\mathrm{C}$ mix, was the $\mathrm{CM}$ had lower compressive strength. This is due to the minimal formation of mycelium, $12.25 \mathrm{~g}$ on day 34, leading to few and inconsistent mycelium fiber networks present in achieving cohesive and better results. In terms of flexural strength as represented by the maximum force on the 3-point bending test, all materials with mycelium attained better results. It shows that the mycelium fibrous network, even if too few for clay materials, can have better flexural resistance. Further investigation is recommended to relate the presence of mycelium and its mechanical properties with different design mixes. 


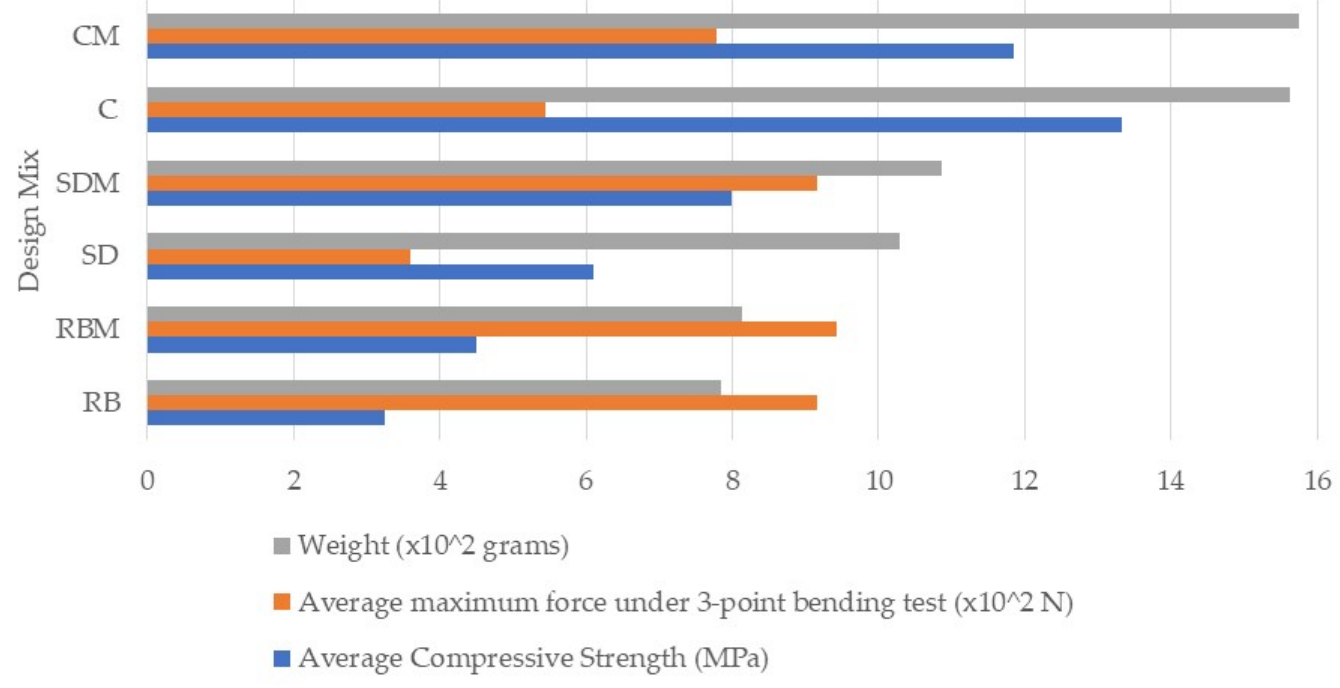

Figure 10. Relationship of mechanical properties and its weight.

\subsection{Dimensional Stability}

Average percentage differences are used to investigate the dimensional stability of mycelium growth in the design mix (i.e., difference on the dimensions of mycelium bricks and non-mycelium bricks divided by non-mycelium bricks multiplied by 100). Three parameters are used in this paper, change in length, change in width, and change in its cross-sectional area. Three measurement readings were made using a caliper, and the averages were taken. Figure 11 shows that all of the lengths and cross-sectional area attained negative percentage differences; it signifies that the length and cross-sectional area with the addition of mycelium made the bricks smaller than non-mycelium bricks. On the other hand, along its width, expansion was observed for all types. Considering length in contraction and width in expansion, the changes in dimension shows a consistent pattern for $\mathrm{CM}$, $\mathrm{RBM}$, and SDM. This phenomenon should be investigated in the future. It proved that the presence of mycelium changes the dimensions of the brick specimens. Based from Section 3.1, the amount of mycelium represented as three difference between mycelium and non-mycelium weight, showed that increasing amount of mycelium is observed from CM, RBM, and SDM which also shows a similar trend with the increase in the changes in its length and width. As a summary, when the mycelium content increases, the linear dimensional change increases. Further studies on the loss of strength and durability against moisture and other environmental factors.

On the other hand, since the compressive properties of bricks are associated with the cross-sectional area, analysis on the change in this dimension is also considered. From Figure 11, it shows that SDM produced the least changes in cross-sectional area, despite having the highest increase in its length and width, by offsetting both changes in its length and width compared to other bricks. Further investigation on its dimensional stability and scalability for industrial use is recommended.

\subsection{Images}

A visual non-destructive test using a stereoscopic microscope was used to examine how the fibers strengthen the developed bricks. To further investigate the damage of the bio-composite bricks, an additional non-destructive test is recommended. Using acoustic emission $[13,14]$ and ultrasonic test $[15,16]$ for damage assessment of construction materials without breaking the test specimens can be practiced with respect to the age and growth of mycelium in the bricks.

The growth of fibers inside the matrix is crucial in determining its mechanical properties. Thus, the researchers utilized the stereoscopic microscope in order to observe a better visualization of mycelium growth in the brick specimens. As seen in Figure 12a, there is a clear mycelium growth in the CM design, but it is less compared to SDM and RBM as observed in Figure 12b,c. There is a 
variation of growth characteristics of mycelium roots as observed in the photos. Meanwhile, Figure 12d exhibits the growth of mycelium in SDM bricks. The fibers were visible throughout the entire material at $50 \times$ magnification. The developed length of the fibers was long capable of binding and holding the particles in the mix together.

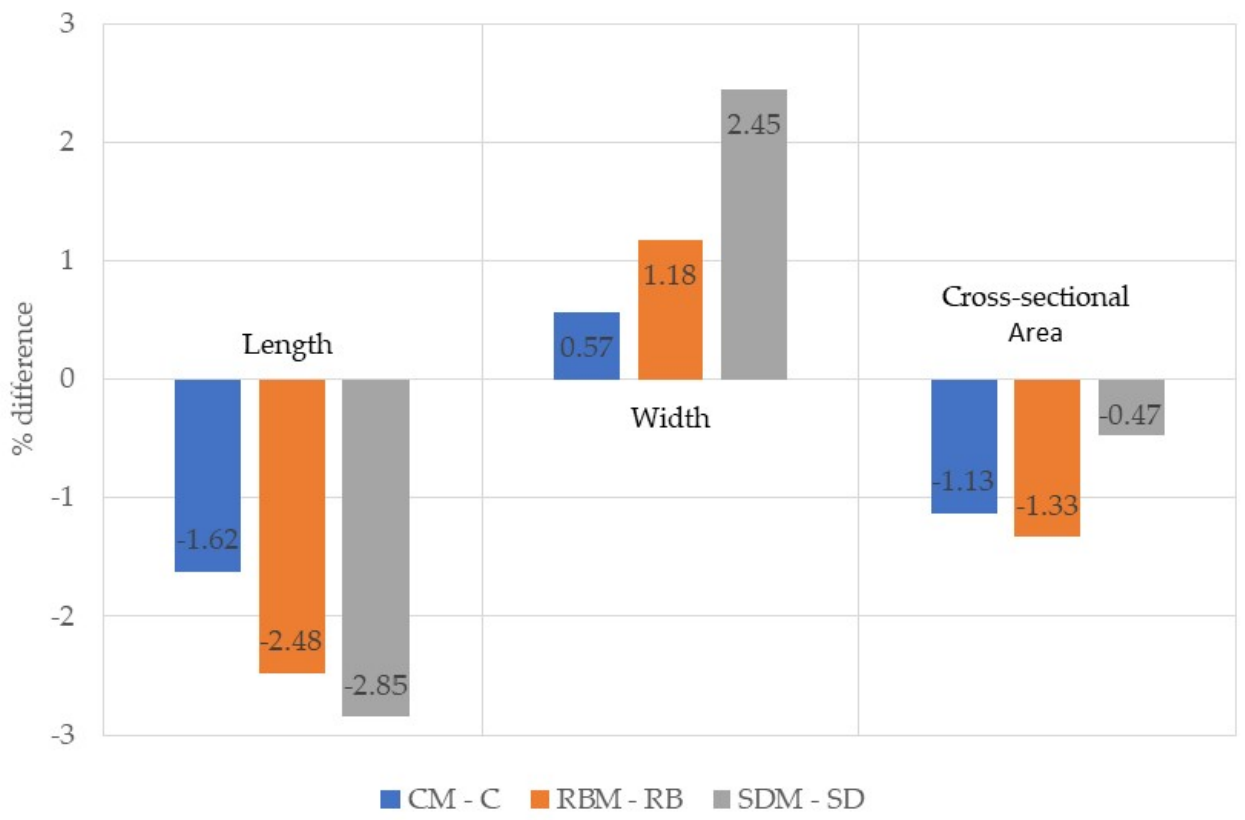

Figure 11. Percentage difference on length, width, and cross-sectional area from non-mycelium bricks.

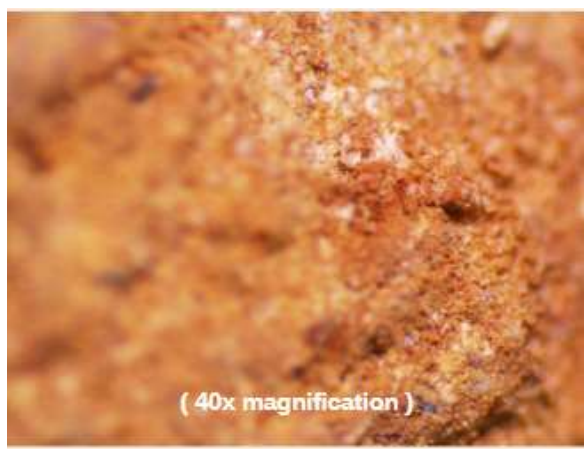

(a)

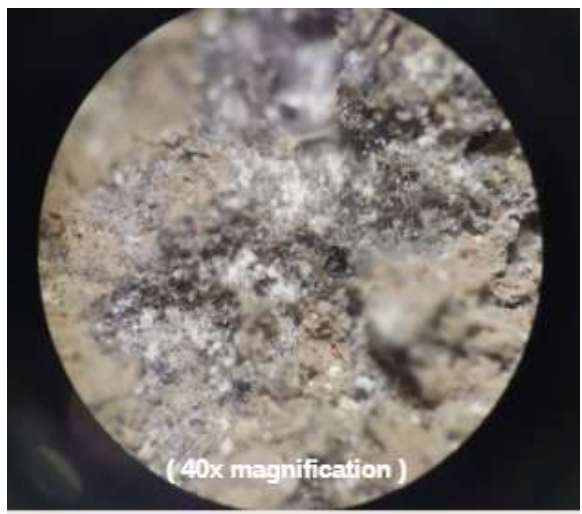

(c)

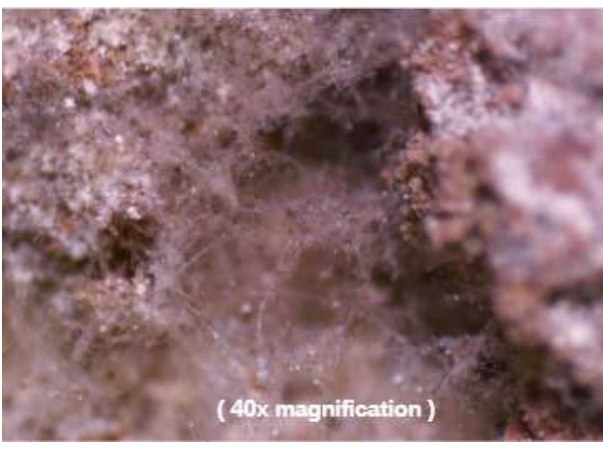

(b)

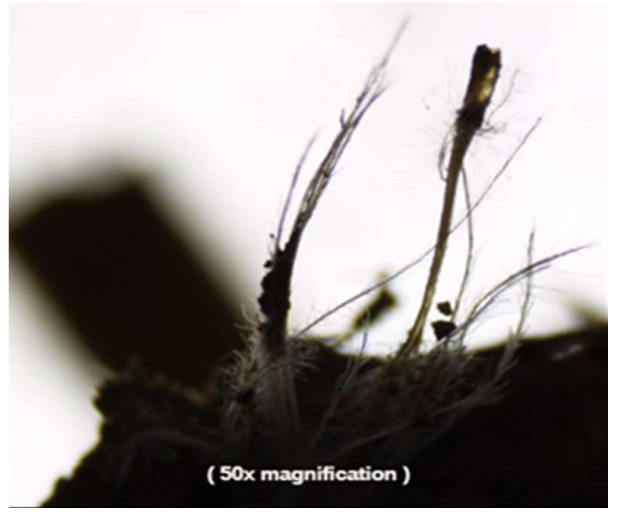

(d)

Figure 12. Stereoscopic images for: (a) Clay with mycelium (CM); (b) sawdust with mycelium (SDM); (c) rice bran with mycelium (RBM); (d) sawdust with mycelium (SDM). 


\section{Conclusions}

The production of bio-composite mycelium bricks as sustainable construction building materials using agricultural waste was achieved. There were six design mixes consisting of rice bran (with and without mycelium), sawdust (with and without mycelium), and pure clay (with or without mycelium). Based on the Indian Standard IS1077, all the brick design mixes with mycelium reached an adequate average compressive strength result and were well above the minimum requirement of 3.5 MPa. Additionally, RBM and SDM obtained a higher compressive strength as compared to their non-mycelium counterparts with an impressive increase of $38.5 \%$ and $31.0 \%$, respectively. The addition of mycelium in the flexural test improves the ductility of the brick specimens by producing fewer cracks. The mycelium content at 34 days of age increases from the design mixes CM, RBM, and SDM. It showed that when the mycelium content increases, the linear dimensional change increases. There is a presence of fiber seen in the stereoscopic microscope, which proved the natural fibers from mycelium acted as a binder to the building material. Future recommendations include the use of material characterization of ingredients, more tests on dimensional stability, more mechanical tests, acoustic tests, water absorption tests, and non-destructive tests with different design mixtures from available agricultural wastes.

Author Contributions: Conceptualization-all authors; methodology-E.I., V.S., C.S., and A.S.; Formal analysis-J.M.C.O., C.S., and A.S.; Investigation-E.I., and V.S.; Resources, E.I., V.S., C.S., and A.S.; Data Curation-E.I., and C.S.; Writing—original draft preparation—all authors; writing, review and editing, J.M.C.O., V.S., A.S.; supervision, J.M.C.O. All authors have read and agreed to the published version of the manuscript.

Funding: This research received no external funding.

Acknowledgments: Emelina H. Mandia for her expertise in the field of Botany and Michael Cagas for his shared knowledge on mycelium production.

Conflicts of Interest: The authors wish to declare no conflict of interest.

\section{References}

1. Abhijith, R.; Ashok, A.; Reejeesh, C.R. Sustainable packaging applications from mycelium to substitute polystyrene: A review. Mater. Todays Proc. 2018, 5, 2139-2145. [CrossRef]

2. Leiva, F.; Saenz-Diez, J.; Martinez, E.; Jimenez, E.; Blanco, J. Environmental impact of Agaricus bisporus mycelium production. Agric. Syst. 2015, 138, 38-45. [CrossRef]

3. Jiang, L.; Walczyk, D.; Mclntyre, G.; Bucinell, R.; Tudryn, G. Manufacturing of biocomposite sandwich structures using mycelium-bound cores and preforms. J. Manuf. Process. 2017, 28, 50-59. [CrossRef]

4. Jones, M.; Huynh, T.; Dekiwadia, C.; Daver, F.; John, S. Mycelium Composites: A Review of Engineering Characteristics and Growth Kinetics. J. Bionanosci. 2017, 11, 241-257. [CrossRef]

5. Attias, N.; Danai, O.; Abitbol, T.; Tarazi, E.; Ezov, N.; Pereman, I.; Grobman, Y.J. Mycelium bio-composites in industrial design and architecture: Comparative review and experimental analysis. J. Clean. Prod. 2020, 246, 119037. [CrossRef]

6. Elsacker, E.; Vandelook, S.; Van Wylick, A.; Ruytinx, J.; De Laet, L.; Peteers, E. A comprehensive framework for the production of mycelium-based lignocellulosic composites. Sci. Total Environ. 2020, 725, 138431. [CrossRef] [PubMed]

7. Dahy, H. Biocomposite materials based on annual natural fibers and biopolymers-Design, fabrication and customized applications in architecture. Constr. Build. Mater. 2017, 147, 212-220. [CrossRef]

8. Gruber, P.; Imhof, B. Patterns of growth-Biomimetics and architectural design. Buildings 2017, 7, 32. [CrossRef]

9. Kuznetsova, I.; Zaitsev, B.; Krasnopolskaya, L.; Teplykh, A.; Semyonov, A.; Avtonomova, A.; Ziangirova, M.; Smirnov, A.; Kolesov, V. Influence of humidity on the acoustic properties of mushroom mycelium films used as sensitive layers for acoustic sensors. Sensors 2020, 20, 2711. [CrossRef] [PubMed]

10. Huarachi, D.A.R.; Goncalves, G.; de Francisco, A.C.; Canteri, M.H.G.; Piekarski, C.M. Life Cycle assessment of traditional and alternative bricks: A review. Environ. Impact Assess. Rev. 2020, 80, 1066335. [CrossRef]

11. Zurbano, L.; Bellere, A.; Savilla, L. Mycelial Growth, Fruiting Body Production and Proximate Composition of Pleurotus djamor on Different Substrate. CLSU Int. J. Sci. Technol. 2017, 2, 7-13. [CrossRef] 
12. Indian Standard Common Burnt Clay Building Bricks—Specification; IS Bureau of Indian Standards: New Delhi, India, 2007; pp. 1-3.

13. Ongpeng, J.; Oreta, A.; Hirose, S. Monitoring damage using acoustic emission source location and computational geometry in reinforced concrete beams. Appl. Sci. 2018, 8, 189. [CrossRef]

14. Ongpeng, J.; Oreta, A.; Hirose, S. Damage progression in concrete using acoustic emission test through convex hull visualization. ACI Materials 2016, 113, 737-744. [CrossRef]

15. Ongpeng, J.; Oreta, A.; Hirose, S. Investigation on the sensitivity of ultrasonic test applied to reinforced concrete beams using neural network. Appl. Sci. 2018, 8, 405. [CrossRef]

16. Ongpeng, J.; Oreta, A.; Hirose, S. Contact and non-contact ultrasonic nondestructive test in reinforced concrete beam. Adv. Civ. Eng. 2018, 5783175.

(C) 2020 by the authors. Licensee MDPI, Basel, Switzerland. This article is an open access article distributed under the terms and conditions of the Creative Commons Attribution (CC BY) license (http://creativecommons.org/licenses/by/4.0/). 